\title{
openheart A prospective, observational, multicentre study comparing tenecteplase facilitated PCI versus primary PCI in Indian patients with STEMI (STEPP - AMI)
}

\author{
Suma M Victor, ${ }^{1}$ Vijayakumar Subban, ${ }^{1}$ Thomas Alexander, ${ }^{2}$ Bahuleyan C G, ${ }^{3}$ \\ Arun Srinivas, ${ }^{4}$ Selvamani $S,{ }^{5}$ Ajit S Mullasari ${ }^{6}$
}

To cite: Victor SM,

Subban V, Alexander T, et al. A prospective, observational, multicentre study comparing tenecteplase facilitated $\mathrm{PCI}$ versus primary $\mathrm{PCl}$ in Indian patients with STEMI (STEPP -AMI). Open Heart 2014;1: e000133. doi:10.1136/ openhrt-2014-000133

- Additional material is available. To view please visit the journal (http://dx.doi.org/ 10.1136/openhrt-2014000133)

The study was conducted by 'Madras Medical Mission', Chennai, India.

Received 13 April 2014 Revised 3 July 2014 Accepted 26 July 2014

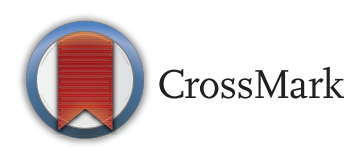

For numbered affiliations see end of article.

Correspondence to Dr Suma M Victor; sumavictor@yahoo.com

\section{ABSTRACT}

Objective: To compare the efficacy of pharmacoinvasive strategy versus primary percutaneous coronary intervention (PCl) in patients with ST-segment elevation myocardial infarction (STEMI). Primary PCI is the preferred treatment for STEMI, but it is not a feasible option for many. A pharmacoinvasive strategy might be a practical solution in the Indian context, although few empirical data exist to guide this approach.

Methods: This is a prospective, observational, multicentre pilot study. Two hundred consecutive patients with STEMI aged 18-75 years, presenting within $12 \mathrm{~h}$ of onset of symptoms and requiring a reperfusion strategy, were studied from five primary $\mathrm{PCl}$ capable centres in South India. Patients who opted for pharmacoinvasive strategy $(n=45)$ formed group $A$. Group B consisted of patients treated with primary PCI $(n=155)$. One patient was lost to follow-up at 1 year. The primary end point was a composite of death, cardiogenic shock, reinfarction, repeat revascularisation of a culprit artery and congestive heart failure at 30 days.

Results: The primary end point occurred in $11.1 \%$ in group $A$ and in $3.9 \%$ in group $B, p=0.07$ ( $R R=2.87$; $95 \% \mathrm{Cl} 0.92$ to 8.97 ). The infarct-related artery patency at angiogram was $82.2 \%$ in group $A$ and $22.6 \%$ in group $B(p<0.001)$. $P C l$ was performed in $73.3 \%$ in group $A$ versus $100 \%$ in group $B(p<0.001)$, and a thrombus was present in $26.7 \%$ in group $A$ versus $63.2 \%$ in group $B(p<0.001)$. Failed fibrinolysis occurred in $12.1 \%$ in group $A$. There was no difference in bleeding risk, $2.2 \%$ in group $A$ versus $0.6 \%$ in group $B$, $(\mathrm{p}=0.4)$.

Conclusions: This pilot study shows that a pharmacoinvasive strategy can be implemented in patients not selected for primary PCl in India and hints at the possibility of similar outcomes. Larger studies are required to confirm these findings.

Trial registration number: Trial is registered with Clinical trial registry of India, CTRI number: REF/2011/ 07/002556.

\section{KEY MESSAGES}

What is already known about this subject?

- Primary $\mathrm{PCl}$ is the preferred treatment for STEMI, but it is not a feasible option for many. A pharmacoinvasive strategy might be a practical solution in the Indian context, although few empirical data exist to guide this approach.

What does this study add?

- This pilot study shows that a pharmacoinvasive strategy can be implemented in patients not selected for primary PCI in India and hints at the possibility of similar outcomes.

How might this impact on clinical practice?

- Pharmacoinvasive strategy may successfully alleviate the logistic or geographical barriers of primary $\mathrm{PCl}$ in the treatment of AMI particularly in a developing country like India.

\section{INTRODUCTION}

Timely reperfusion is the most effective treatment for the ST-segment elevation myocardial infarction (STEMI). ${ }^{1}$ It has been shown in randomised trials to limit the amount of myocardial damage, which in turn results in better left ventricular function and low mortality. ${ }^{2}$ Reperfusion can be achieved through either pharmacological or mechanical means. The non-fibrin-specific thrombolytic agent streptokinase was less effective in opening the infarct-related artery (IRA), but the introduction of fibrin-specific lytic agentslike tenecteplase (TNK) has improved the patency rates substantially. ${ }^{3}$ Although they are widely available, reocclusion of the IRA continues to be a major problem. In contrast, primary percutaneous coronary 
intervention (PCI) achieves immediate and sustained patency of the IRA and has been consistently shown to be superior to the thrombolytic treatment. ${ }^{4}$ However, unavailability and transport delays have restricted primary PCI to only a small proportion of eligible patients. Initial timely fibrinolysis to open the IRA followed by early PCI-that is, a pharmacoinvasive strategy-to improve the patency rates is an attractive approach, particularly in developing countries like India where catheterisation facilities are limited to major cities. Randomised studies have shown the feasibility and safety of this approach in STEMI in comparison with primary PCI. ${ }^{5}$ The current study is a non-randomised study largely designed to assess the safety and feasibility of a pharmacoinvasive strategy in comparison to primary PCI.

\section{MATERIALS AND METHODS}

\section{Aim}

To compare the efficacy of prompt fibrinolysis coupled with contemporary antiplatelet and antithrombotic therapy at first medical contact followed by timely catheterisation in patients with STEMI within $12 \mathrm{~h}$ of symptom onset (ie, a pharmacoinvasive strategy) in comparison with standard primary PCI.

\section{Study design}

This is a prospective, observational, multicentre pilot study which was conducted from August 2011 to May 2013. We carried out this study as there is a strong rationale for assessing feasibility through piloting the pharmacoinvasive strategy in Indian patients presenting with STEMI, as there is little that is known about the same. The study sites are situated in South India; three sites are from the state of Tamil Nadu, one from the state of Karnataka and one from the state of Kerala. All study sites were well equipped with $24 / 7$ facility of performing primary PCI with the aid of expert interventional cardiologists. A total of 200 patients diagnosed to have STEMI were enrolled into the study based on the inclusion/ exclusion criteria. No randomisation for this study was performed due to ethical reasons, as most Indian patients with STEMI have longer presentation times compared with patients from developed countries. ${ }^{6}$ Although all participating hospitals are primary PCI capable hospitals, some patients opted for a pharmacoinvasive approach. The main reason for this is lack of ready finances. Comprehensive insurance coverage for all comers with STEMI was not available at all participating centres during the period of the study as STEMI care was not linked to insurance. Applying for insurance or arranging for out of pocket expenses needed time; hence, patients opted for a thrombolysis initially, and then went ahead with catheterisation and PCI once the insurance approval came or money could be arranged. This was the reason in the majority of patients who went through the pharmacoinvasive strategy. In a minority of patients, the catheterisation laboratory was not available at the time of the patient's arrival. (Out of 45 patients in group A, only one patient underwent the pharmacoinvasive approach because the catheterisation laboratory was occupied.) Failed thrombolysis is defined as persisting or worsening chest pain or $<50 \%$ resolution of ST-segment elevation after $90 \mathrm{~min}$ of thrombolysis in a single lead showing maximum ST-segment elevation at presentation. Written informed consent was signed by all patients.

The inclusion criteria were the following: adults aged 18-75 years with STEMI requiring either primary PCI or fibrinolysis with TNK, patients presenting with the onset of symptoms within $12 \mathrm{~h}$, subjects/legally acceptable representative or impartial witness (if applicable) must be able to understand and provide their consent in the informed consent form. If a patient with STEMI has unstable haemodynamics or is not willing to read and sign the informed consent during initial presentation, then a legally acceptable representative, that is, a family member, could initially sign the informed consent. As we still have illiterate patients and family members in India, we often use a person who is not related to the study to read out the informed consent to the patient and the family members and then obtain a thumb print from them. The person who reads the consent is often called the 'impartial witness' and needs to sign the informed consent form as well. Patients who were participating in any other study or who were unwilling to comply with the protocol were excluded.

\section{End points}

The primary end point was a composite of death, cardiogenic shock, reinfarction, repeat revascularisation of the culprit artery and congestive heart failure at 30 days. The safety end points are bleeding end points assessed using the thrombolysis in myocardial infarction (TIMI) classification at 30 days.

Definitions used in the study are given in the online supplementary appendix.

\section{Study protocol}

Data were collected by personnel who were blinded to the study objectives and recorded the same in specially designed electronic case report form (eCRF). Each patient was given a screening number to maintain anonymity. Demographic details and baseline characteristics of the patient population were documented meticulously. Relevant medical history, salient clinical examination findings, laboratory investigations including cardiac biomarkers, ECG and echocardiogram findings were noted. Details of medication prescribed were also collected. Patients who were fibrinolysed with TNK were in group A and patients who underwent primary PCI formed group B. Figure 1 depicts the study flow. In group A, the timing and dosage of TNK was documented, and TNK was administered as per the recommended dosage based on the body weight of the patient, $30 \mathrm{mg}$ if the weight is $<60 \mathrm{~kg}, 35 \mathrm{mg}$ if the weight is $60-70 \mathrm{~kg}, 40 \mathrm{mg}$ if the weight is $70-80 \mathrm{~kg}, 45 \mathrm{mg}$ if the 
Figure 1 Study protocol of Study comparing TEnecteplase facilitated $\mathrm{PCl}$ versus Primary $\mathbf{P C l}$ in Indian patients with Acute Myocardial Infarction (STEPP. AMI). ASA, Aspirin; TNK, Tenecteplase; $\mathrm{PCl}$, percutaneous coronary intervention; LD, loading dose; OD, once daily; LMWH, low-molecular-weight heparin. *Please refer to the text for the definition of failed thrombolysis.

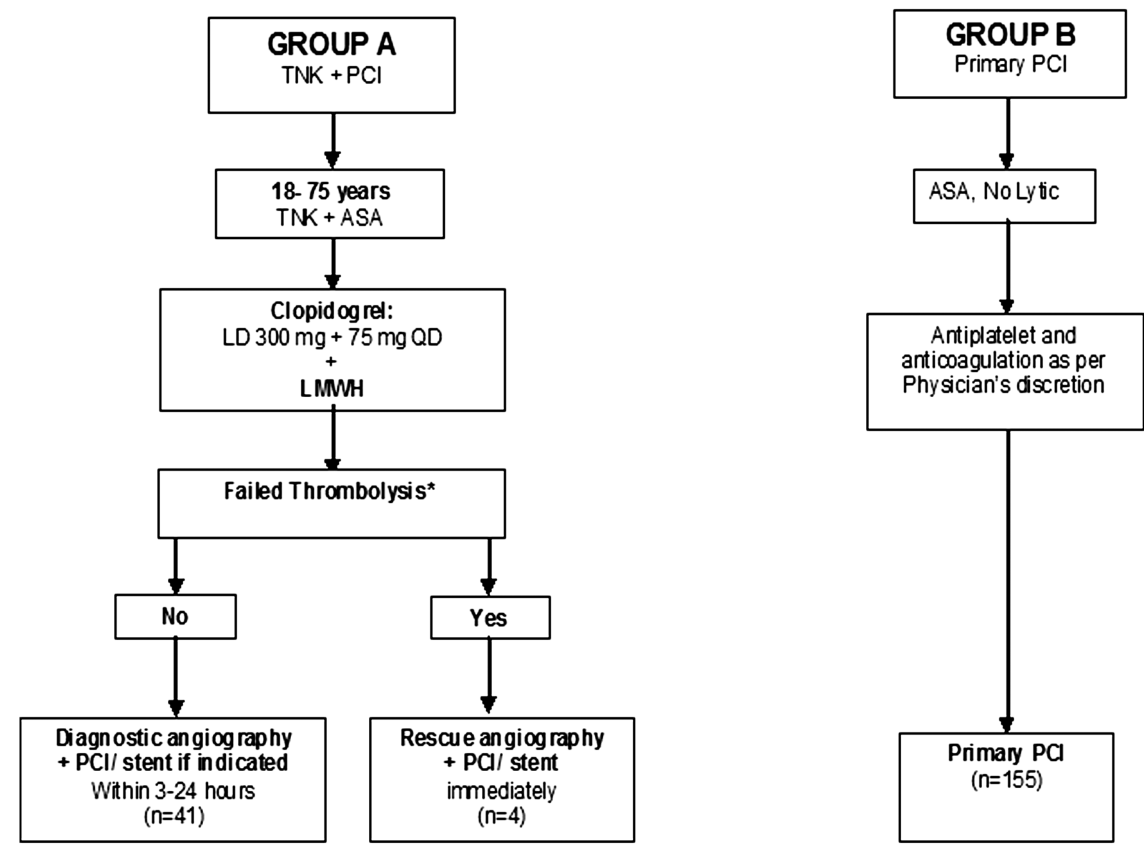

weight is $80-90 \mathrm{~kg}$ and $50 \mathrm{mg}$ if the weight is $>90 \mathrm{~kg}$. In case of failed thrombolysis, rescue PCI was performed at the investigator's discretion. The time to a coronary angiogram (CAG) with or without intervention, time from symptom onset to hospital presentation, door-to-balloon time, door-to-needle time and total ischaemic time were documented. During the procedure, the access site, whether or not thrombosuction was performed, the number of vessels diseased, the number of vessels stented, the type of stent used, the reasons for not performing angioplasty if the procedure was not conducted, the procedure complications if any, the adjuvant medication, the use of intra-aortic balloon pulsation and the outcome of the procedure were noted. The IRA patency, TIMI flow in IRA preprocedure and postprocedure, thrombus burden and procedure success were evaluated by a blinded investigator. Bleeding events were classified using TIMI bleeding criteria.

At discharge, patients' clinical status and prescription details were also noted. Follow-up was done at the clinic at 30 days, and telephonically at 3, 6 and 12 months. During follow-up angina status, functional status and details about any reportable events were collected.

\section{Statistical analysis}

A sample size of 200 patients was enrolled as this was a pilot study primarily designed to assess feasibility. Data from all five study sites were combined for analysis. All statistical analyses were performed using SAS software, V.9.2. Continuous data were presented as $\mathrm{n}$ (observation count), mean, SD, minimum, median and maximum. Categorical data and the number and percentage of participants in each category were reported. We used frequency and cross tabulation to explore differences across different factors. Continuous variables were tested using the Student $\mathrm{t}$ test and the categorical variables were tested using the $\chi^{2} /$
Fischer's test for the relation between each individual factor and treatment group at 5\% level of significance. The total ischaemic time between the two groups was compared using the median test at 5\% level of significance. Relative risk estimates were calculated along with $95 \%$ CIs and provided in the appropriate tables along with adjustments for important covariates. The Kaplan-Meier curves with log rank test were used to compare differences in outcomes as well. A p value of 0.05 was considered significant for all statistical evaluations.

\section{RESULTS}

A total of 200 patients were enrolled into this pilot study. Group A $(n=45)$ comprised patients who were treated with the pharmacoinvasive strategy, and group B $(n=155)$ included patients who underwent primary PCI. At the end of 1 year, one patient was lost to follow-up in group A $(0.5 \%)$. There is no difference between the baseline characteristics of two groups, except that more patients in group B were in Killip's class 1 (table 1). Diabetes mellitus is the most prevalent risk factor at $53.3 \%$ (group A) and $50.3 \%$ (group B). Only $13.5 \%$ of the total patients were female.

In group B, $100 \%$ patients underwent PCI with stenting (table 2). In group A, 95.5\% $(n=43)$ of patients underwent coronary angiography. $82.2 \% \quad(n=37)$ had open IRA, $12.1 \%(n=4)$ of patients had failed fibrinolysis and had to undergo urgent catheterisation. PCI was performed in $73.3 \%(n=37)$ of patients, as $2(4.4 \%)$ patients died before the catheterisation could be performed, 2 $(4.4 \%)$ patients who were in cardiogenic shock died during the procedure and $6.7 \%(n=3)$ of patients had insignificant disease; hence, no intervention was performed; $4.4 \%(n=2)$ were not willing for an intervention and $6.7 \%(n=3)$ had diffuse triple vessel disease. The 
Table 1 Baseline characteristic between the two groups

\begin{tabular}{|c|c|c|c|}
\hline Variable & $A(n=45)$ & $B(n=155)$ & p Value \\
\hline \multicolumn{4}{|l|}{ Age, in years } \\
\hline Median & 54 & 54 & 0.74 \\
\hline IQR & $46-62$ & $47-61$ & \\
\hline \multicolumn{4}{|l|}{ Weight, kg } \\
\hline Median & 65 & 65 & 0.88 \\
\hline IQR & $60-71.5$ & $60-70$ & \\
\hline Killip class, n (\%) & & & 0.002 \\
\hline 1 & $20(44.4)$ & $110 / 155(71)$ & \\
\hline 2 & 19 (42.2) & $34(21.9)$ & \\
\hline 3 & $5(11.1)$ & $11(7.1)$ & \\
\hline 4 & $1(2.2)$ & 0 & \\
\hline Male, n (\%) & $39(86.7)$ & $134(86.5)$ & 0.97 \\
\hline Female, n (\%) & $6(13.3)$ & $21(13.5)$ & \\
\hline Dyslipidemia, n (\%) & $5(11.1)$ & $7(4.5)$ & 0.14 \\
\hline Hypertension, n (\%) & $14(31.1)$ & $47(30.3)$ & 0.91 \\
\hline Diabetes, n (\%) & $24(53.3)$ & $78(50.3)$ & 0.72 \\
\hline Smoking history, n (\%) & $12(26.7)$ & 35 (22.6) & 0.56 \\
\hline Family history, n (\%) & $3(6.7)$ & 19 (12.3) & 0.29 \\
\hline CVA/TIA, n (\%) & 0 & 0 & NA \\
\hline CKD, n (\%) & $2(4.4)$ & $5(3.2)$ & 0.69 \\
\hline
\end{tabular}

Table 2 Procedural characteristics of the two groups

\begin{tabular}{|c|c|c|c|}
\hline Intervention & $A(n=45)$ & $B(n=155)$ & p Value \\
\hline Number of vessel diseases, $\mathrm{n}(\%)$ & & & 0.007 \\
\hline Single vessel disease, $\mathrm{n}(\%)$ & $30(66.7)$ & $113(73.3)$ & \\
\hline Double vessel disease, n (\%) & $5(11.1)$ & $11(7.1)$ & \\
\hline Triple vessel disease, $\mathrm{n}(\%)$ & $7(15.5)$ & $31(20.1)$ & \\
\hline Insignificant disease, $\mathrm{n}(\%)$ & $3(6.7)$ & 0 & \\
\hline Culprit lesion, $n(\%)$ & & & 0.10 \\
\hline LAD & $25(55.5)$ & $91(58.7)$ & \\
\hline LCX & $2(4.4)$ & $13(8.4)$ & \\
\hline RAMUS & $1(2.2)$ & $1(0.6)$ & \\
\hline RCA & 15 (33.3) & $50(32.2)$ & \\
\hline IRA patency, n (\%) & & & $<0.0001$ \\
\hline Closed & $6(13.3)$ & $120(77.4)$ & \\
\hline Open & $37(82.2)$ & $35(22.6)$ & \\
\hline Thrombus present, n (\%) & $12(26.7)$ & $98(63.2)$ & $<0.0001$ \\
\hline $\mathrm{PCl}$ performed, $\mathrm{n}(\%)$ & 33 (73.3) & $155(100)$ & $<0.0001$ \\
\hline Failed thrombolysis, $\mathrm{n}(\%)$ & $4(12.1)$ & NA & \\
\hline Type of stent, $n(\%)$ & & & 0.85 \\
\hline BMS & $14(42.3)$ & $62(40)$ & \\
\hline DES & $19(57.6)$ & $93(60)$ & \\
\hline Preprocedure TIMI flow, n (\%) & $(n=43)$ & $(n=155)$ & $<0.0001$ \\
\hline 0 & $5(11.6)$ & $112(72.3)$ & \\
\hline 1 & $1(2.3)$ & $11(7.1)$ & \\
\hline 2 & $25(58.1)$ & $25(16.1)$ & \\
\hline 3 & $12(27.9)$ & $7(4.5)$ & \\
\hline NA & $2(4.4)$ & 0 & \\
\hline Postprocedure TIMI flow, n (\%) & $(n=33)$ & $(n=155)$ & 0.35 \\
\hline 1 & 0 & $1(0.6)$ & \\
\hline 2 & $14(42.4)$ & $108(69.7)$ & \\
\hline 3 & 19 (57.6) & $46(29.7)$ & \\
\hline Access site, $n(\%)$ & & & $<0.0001$ \\
\hline Femoral & $10(23.3)$ & $90(58.1)$ & \\
\hline Radial & 33 (76.7) & 65 (41.9) & \\
\hline
\end{tabular}

BMS, bare metal stent; DES, drug eluting stent; IRA, infarct-related artery; LAD, left anterior descending artery; LCX, left circumflex artery; $\mathrm{NA}$, not applicable; PCl, percutaneous coronary intervention; RAMUS, ramus intermedius; RCA, right coronary artery; TIMI, thrombolysis in myocardial infarction. 
Table 3 Important timelines for the study

\begin{tabular}{llll}
\hline Parameter & A & B & p Value \\
\hline Total ischaemic time (min) & & 260 & 0.69 \\
Median & 245 & $185-390$ \\
IQR & $185-395$ & - & NA \\
Time to pharmacoinvasive strategy (h) & $12: 15(4: 30-23: 40)$ & 80 & NA \\
Door-to-balloon time (min) & - & $60-120$ \\
$\quad$ Median & - & - & NA \\
IQR & 47 & - \\
Door-to-needle time (min) & $35-75$ &
\end{tabular}

other procedural details are given in table 2. Patients in group A also had better TIMI flow at CAG (TIMI 3 flow in $27.9 \%$ ) and had more IRA patency $(82.2 \%)$ and less thrombus burden.

The total ischaemic time, door-to-balloon time and the door-to-needle time are given in table 3.The use of medications is given in table 4 . The efficacy end points are enlisted at 30 days, 3 months, 6 months and 1 year (tables 5 and 6 ). The safety end points are given in table 7: there is $2.2 \%(\mathrm{n}=1)$ bleeding in group $\mathrm{A}$ from the access site and there is $0.6 \% \quad(n=1)$ bleeding in group B. The cumulative event rates for the primary end point are shown in figure 2.

\section{DISCUSSION}

Primary PCI is the preferred method of revascularisation in STEMI management where feasible. However, its population-wide availability is limited due to various factors, especially in a developing country like India. A pharmacoinvasive strategy has been studied as a valuable alternative to primary PCI for $\mathrm{STEMI}^{7} 8$ and can be

\begin{tabular}{lccc}
\multicolumn{4}{l}{ Table 4 Medication details } \\
\hline Medication used & A & B & p Value \\
\hline Aspirin LD, n (\%) & $45(100)$ & $155(100)$ & NA \\
Aspirin OD, n (\%) & $45(100)$ & $155(100)$ & NA \\
Clopidogrel LD, n (\%) & $45(100)$ & $130(83.8)$ & $<0.001$ \\
Clopidogrel, n (\%) & $45(100)$ & $123(79.3)$ & 0.0001 \\
Prasugrel, n (\%) & 0 & $33(21.3)$ & 0.0001 \\
Statin, n (\%) & $45(100)$ & $155(100)$ & NA \\
B-blocker, n (\%) & $27(60)$ & $117(75.5)$ & 0.042 \\
ACE-I/ARB, n (\%) & $24(53.3)$ & $98(63.2)$ & 0.21 \\
CCB, n (\%) & $10(22.2)$ & $23(14.8)$ & 0.24 \\
LWMH, n (\%) & $43(95.6)$ & $111(71.6)$ & 0.0005 \\
Antianginal drug, n (\%) & $15(33.3)$ & $79(50.9)$ & 0.037 \\
GPIIb/IIla use, n (\%) & $3(6.7)$ & $67(43.2)$ & $<0.0001$ \\
\hline Antangina drs include nitrat
\end{tabular}

Antiangina drugs include nitrates, trimetazidine and ranolazine. ACE-I, ACE inhibitor; ARB, angiotensin receptor blockers; CCB, calcium channel blockers; GP, glycoprotein; LD, loading dose; LMWH, low molecular weight heparin; NA, not applicable; OD, once daily. utilised to prevent time lag in availing appropriate reperfusion.

In this study, 200 patients with STEMI who underwent either primary PCI or a pharmacoinvasive strategy within $12 \mathrm{~h}$ of symptom onset were followed up until 1 year. The primary end point, which is a composite of death, cardiogenic shock, reinfarction, repeat revascularisation of the culprit artery and congestive heart failure, was no different between both groups at 30 days, 3 months, 6 months and 1 year, although there is a trend towards benefit from primary PCI during the early phase of follow-up, in spite of the fact that relatively affluent patients underwent primary PCI; hence, this group is expected to have better long-term outcomes due to lifestyle changes and better adherence to medication. The lack of statistical significance between both groups may be due to the limited sample size. Similar findings were reported in the STREAM study, ${ }^{9}$ which randomised patients with STEMI presenting within $3 \mathrm{~h}$ of symptom onset, who could not undergo primary PCI within $1 \mathrm{~h}$ of presentation, into primary PCI and pharmacoinvasive groups. The primary end point, a composite of any death, shock, reinfarction or congestive heart failure, was similar between both groups at 30 days. Previous clinical trials comparing the efficacy of both the reperfusion modalities in STEMI have shown a time dependent benefit of thrombolysis up to $3 \mathrm{~h} .{ }^{10}{ }^{11}$ In the STREAM trial, the total ischaemic time in the pharmacoinvasive arm was 100 min. ${ }^{9}$ In our study, the end points were comparable, despite a total ischaemic time of $245 \mathrm{~min}$ in the fibrinolytic subset. However, we need larger randomised controlled trials (RCTs) to confirm this benefit. Other efficacy end points like death and death or reinfarction were also similar in both groups.

A significant number of patients in group A did not require a stent implantation due to insignificant disease $(6.7 \%)$. In a recent study, which was not an RCT, Kelbæk et $a l^{12}$ demonstrated that deferred stent implantation in STEMI is a feasible option. Thirty-eight per cent of patients in that study had $<30 \%$ residual stenosis. More interestingly, patients in group A also had better IRA patency rates and a lower thrombus burden at 
Table 5 Efficacy end points

\begin{tabular}{|c|c|c|c|c|c|}
\hline \multirow[b]{2}{*}{ End points } & \multirow{2}{*}{$\begin{array}{l}A \\
(n=45) \\
n(\%)\end{array}$} & \multirow{2}{*}{$\begin{array}{l}B \\
(n=155) \\
n(\%)\end{array}$} & \multirow[b]{2}{*}{ p Value } & \multicolumn{2}{|c|}{ Relative risk } \\
\hline & & & & Estimate & $95 \% \mathrm{Cl}$ \\
\hline \multicolumn{6}{|c|}{ Death, reinfarction, repeat revascularisation of the culprit artery, cardiogenic shock, CHF } \\
\hline At 30 days & $5(11.1)$ & $6(3.9)$ & 0.07 & 2.87 & 0.92 to 8.97 \\
\hline At 3 months & $6(13.3)$ & $9(5.8)$ & 0.10 & 2.30 & 0.86 to 6.11 \\
\hline At 6 months & $6(13.3)$ & $11(7.1)$ & 0.19 & 1.88 & 0.74 to 4.80 \\
\hline At 1 year & $6(13.3)$ & $14(9.0)$ & 0.40 & 1.48 & 0.60 to 3.62 \\
\hline \multicolumn{6}{|c|}{ Efficacy end point-death } \\
\hline At 30 days & $3(6.7)$ & $2(1.3)$ & 0.07 & 5.17 & 0.89 to 29.98 \\
\hline At 3 months & $4(8.9)$ & $4(2.6)$ & 0.07 & 3.44 & 0.90 to 13.23 \\
\hline At 6 months & $4(8.9)$ & $5(3.2)$ & 0.12 & 2.76 & 0.77 to 9.83 \\
\hline At 1 year & $4(8.9)$ & $7(4.5)$ & 0.26 & 1.97 & 0.60 to 6.42 \\
\hline \multicolumn{6}{|c|}{ Efficacy end point-death/reinfarction } \\
\hline At 30 days & $3(6.7)$ & $5(3.2)$ & 0.31 & 2.07 & 0.51 to 8.32 \\
\hline At 3 months & $4(8.9)$ & $7(4.5)$ & 0.26 & 1.97 & 0.60 to 6.42 \\
\hline At 6 months & $4(8.9)$ & 8 (5.2) & 0.36 & 1.72 & 0.54 to 5.46 \\
\hline At 1 year & 4 (8.9) & $10(6.4)$ & 0.57 & 1.38 & 0.45 to 4.18 \\
\hline
\end{tabular}

catheterisation when compared with studies of fibrinolytic therapy in other healthcare systems and countries. This may relate to differences in patients with STEMI in India; however, these findings merit further evaluation. The occurrence of failed thrombolyis requiring urgent CAG was $12.1 \%$ in this study, much lesser than that reported in the STREAM trial $(36.3 \%)$. Interestingly, the mortality rate in the pharmacoinvasive group was at a standstill after the first 3 months $(6.7 \%$ at 30 days, and $8.9 \%$ at 3 months, 6 months and 1 year), while in the primary PCI group patients it continued to increase (1.3\% at 30 days, $2.6 \%$ at 3 months, $3.2 \%$ at 6 months and $4.5 \%$ at 1 year). This may be due the fact that $6.7 \%$ of patients in the facilitated group did not require a stent as they had insignificant disease on the angiogram; although only one patient from this group was lost to

Table 6 Efficacy end points (after adjusting for age, sex, Killip class as covariates)

\begin{tabular}{|c|c|c|c|c|c|}
\hline \multirow[b]{2}{*}{ End points } & \multirow{2}{*}{$\begin{array}{l}A \\
(n=45) \\
n(\%)\end{array}$} & \multirow{2}{*}{$\begin{array}{l}B \\
(n=155) \\
n(\%)\end{array}$} & \multirow[b]{2}{*}{ p Value } & \multicolumn{2}{|c|}{ Relative risk } \\
\hline & & & & Estimate & $95 \% \mathrm{Cl}$ \\
\hline \multicolumn{6}{|c|}{ Death, reinfarction, repeat revascularisation, cardiogenic shock, CHF } \\
\hline At 30 days & $5(11.1)$ & $6(3.9)$ & 0.12 & 2.22 & 0.81 to 6.13 \\
\hline At 3 months & $6(13.3)$ & $9(5.8)$ & 0.23 & 1.70 & 0.72 to 4.05 \\
\hline At 6 months & $6(13.3)$ & $11(7.1)$ & 0.34 & 1.50 & 0.65 to 3.43 \\
\hline At 1 year & $6(13.3)$ & $14(9.0)$ & 0.64 & 1.21 & 0.54 to 2.71 \\
\hline
\end{tabular}

\section{Table 7 Safety end points}

\begin{tabular}{llll}
\hline & A & B & p Value \\
\hline Bleeding & & & $1(0.6)$ \\
Any bleeding, $\mathrm{n}(\%)$ & $1(2.2)$ & 0 & $\mathrm{NA}$ \\
Intracranial bleeding, $\mathrm{n}$ & 0 & 0 & 0.22 \\
Bleeding at access site, $\mathrm{n}(\%)$ & $1(2.2)$ & $1(0.6)$ & 1.0 \\
TIMI bleeding & & 0 & $\mathrm{NA}$ \\
Major, $\mathrm{n}(\%)$ & 0 & 0 & 0.22 \\
Requiring medical attention, $\mathrm{n}(\%)$ & 0 & & \\
Minimal, $\mathrm{n}(\%)$ & $1(2.2)$ & &
\end{tabular}




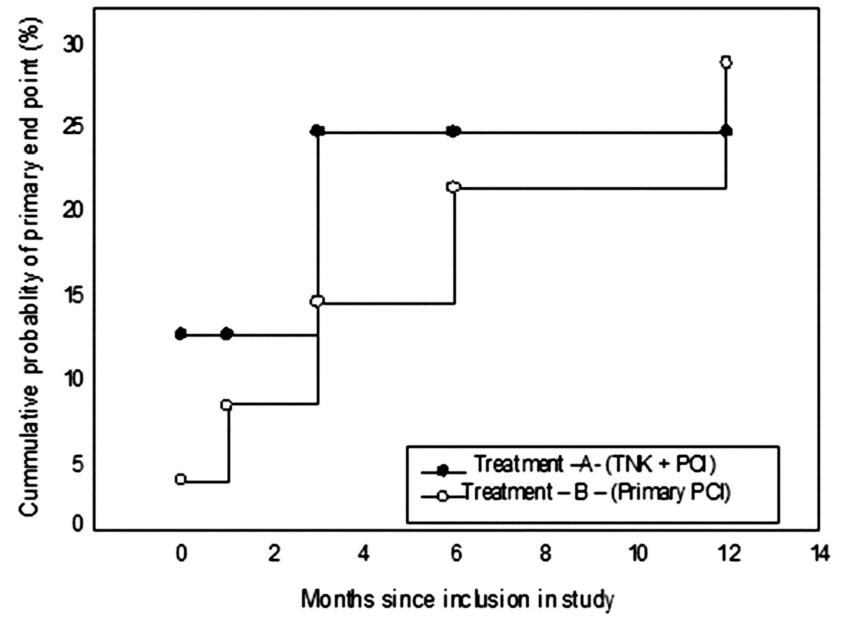

Figure 2 Kaplan-Meier curves for the primary end point. The primary end point was a composite of death, cardiogenic shock, reinfarction, repeat revascularisation of the culprit artery and congestive heart failure at 30 days, distribution between the two groups tested using a log rank test $(p=0.36)$. TNK, Tenecteplase; $\mathrm{PCl}$, percutaneous coronary intervention.

follow-up, this may also have contributed since the study has a small sample size. Fibrinolytic therapy is shown to be associated with increase in bleeding risk, especially haemorrhagic strokes in few trials. ${ }^{9} 13$ In our study, there is no difference in bleeding risk between both groups. This may be due to the fact that more number of patients in the fibrinolytic group had radial access for catheterisation compared with the primary PCI group $(76.7 \%$ vs $41.9 \%) .{ }^{14}$ We have excluded patients aged $>75$ years and only $13 \%$ of patients are female; it is predominantly in these subsets that there was an increase in bleeding risk. ${ }^{9}$ However, this may also be due to the fact that this study did not demonstrate the difference in bleeding risk due to its small sample size.

\section{Limitations}

Our study has a few limitations. This is an observational pilot study with a small sample size and the study groups were not randomised. The risk of bleeding in the pharmacoinvasive group may be low as the study excluded patients above 75 years of age, and our findings are not generalisable to older patients. Owing to the small sample size of the study, our findings may not provide a precise estimate of outcomes (especially safety end points) and definitive conclusions await larger randomised trials.

In summary, the results of this observational study show that a pharmacoinvasive strategy can be implemented safely in patients under the age of 75 years who do not undergo primary PCI in India. These findings obviously require additional investigation, given the limited sample size. A pharmacoinvasive strategy may successfully alleviate the logistic or geographical barriers of primary PCI in the treatment of AMI, particularly in a developing country like India.
Author affiliations

${ }^{1}$ Madras Medical Mission, Chennai, Tamil Nadu, India

${ }^{2}$ Kovai Medical Center and Hospital, Coimbatore, Tamil Nadu, India

${ }^{3}$ Cardiovascular Centre, Ananthapuri Hospitals and Research Institute,

Trivandrum, Kerala, India

${ }^{4}$ Department of Cardiology, Vikram Group of Hospitals, Mysore, Karnataka, India

${ }^{5}$ Meenakshi Mission Hospital and Research Centre, Madurai, Tamil Nadu, India

${ }^{6}$ Madras Medical Mission, Chennai, Tamil Nadu, India

Acknowledgements The author would like to thank Mr Manikandasamy, Dr Kala Subramaniam and Dr Saral Thangam for their support and encouragement and acknowledge Ms Marutha Priya, Mr Vigna Prasad and Ms Kamaleshwari for their meticulous data collection.

Contributors ASM contributed to the conception of trial design and final correction and approval of the version. SMV contributed to the conception of trial design and drafting of the article. VS contributed to the drafting of tables and images and analysis. TA contributed to the conception of trial design and analysis of data. BCG and AS provided important intellectual content. SS contributed to the statistical inputs and revised the article critically.

Funding This research received no specific grant from any funding agency in the public, commercial or not-for-profit sectors. Tenecteplase has been provided free of cost for patients participating in this trial by Boehringer Ingelheim.

\section{Competing interests None.}

Ethics approval The study has been cleared by the ethics committees of the respective hospitals.

Provenance and peer review Not commissioned; externally peer reviewed.

Data sharing statement No additional data are available.

Open Access This is an Open Access article distributed in accordance with the Creative Commons Attribution Non Commercial (CC BY-NC 4.0) license, which permits others to distribute, remix, adapt, build upon this work noncommercially, and license their derivative works on different terms, provided the original work is properly cited and the use is non-commercial. See: http:// creativecommons.org/licenses/by-nc/4.0/

\section{REFERENCES}

1. Steg PG, James SK, Atar D, et al. ESC guidelines for the management of acute myocardial infarction in patients presenting with ST-segment elevation. Eur Heart J 2012;33:2569-619.

2. Stone GW. Angioplasty strategies in ST-segment-elevation myocardial infarction. Part I: primary percutaneous coronary intervention. Circulation 2008;118:538-51.

3. lyengar SS, Nair T, Sathyamurthi I, et al. Efficacy and safety of tenecteplase in STEMI patients from ELAXIM Indian registry. Indian Heart J 2009;61:480-1.

4. Andersen HR, Nielsen TT, Rasmussen K, et al. A comparison of coronary angioplasty with fibrinolytic therapy in acute myocardial infarction. N Engl J Med 2003;349:733-42.

5. Armstrong PW, Boden WE. Reperfusion paradox in ST-segment elevation myocardial infarction. Ann Intern Med 2011;155:389-91.

6. Xavier D, Pais $\mathrm{P}$, Devereaux PJ, et al. CREATE registry investigators. Treatment and outcomes of acute coronary syndromes in India (CREATE): a prospective analysis of registry data. Lancet 2008;371:1435-42.

7. Kushner FG, Hand M, Smith SC, et al. 2009 Focused Updates: ACC/AHA Guidelines for the Management of Patients with ST-Elevation Myocardial Infarction (Updating the 2004 Guideline and 2007 Focused Update) and ACC/AHA/SCAI Guidelines on Percutaneous Coronary Intervention (Updating the 2005 Guideline and 2007 Focused Update). J Am Coll Cardiol 2009;54:22052241.

8. Pakshirajan B, Subban V, Mullasari AS. Pharmacoinvasive management. Interv Cardiol Clin 2012;1:409-19.

9. Armstrong PW, Gershlick AH, Goldstein P, et al:; for the STREAM Investigative Team. Fibrinolysis or primary PCI in ST-segment elevation myocardial infarction. N Engl J Med 2013;368:1379-87.

10. Steg PG, Bonnefoy E, Chabaud S, et al. Comparison of Angioplasty and Prehospital Thrombolysis in Acute Myocardial infarction (CAPTIM) Investigators Impact of time to treatment on mortality after 
prehospital fibrinolysis or primary angioplasty: data from the CAPTIM randomized clinical trial. Circulation 2003;108:2851-6.

11. Hanna E, Hennebry TA, Abdu-Fadel MS. Combined reperfusion strategies in ST-segment elevation Ml: rationale and current role. Cleve Clin J Med 2010;77:629-38.

12. Kelbæk H, Engstrøm T, Ahtarovski KA, et al. Deferred stent implantation in patients with ST-segment elevation myocardial infarction: a pilot study. Eurolntervention 2013;8:1126-33.
13. Van de Werf F, Barron HV, Armstrong PW, et al. Incidence and predictors of bleeding events after fibrinolytic therapy with fibrin-specific agents: a comparison of TNK-tPA and rt-PA. Eur Heart J 2001;22:2253-61.

14. Jolly SS, Yusuf S, Cairns J, et al. Radial vs. femoral access for coronary angiography and intervention in patients with acute coronary syndromes (RIVAL): a randomised, parallel group multicentre trial. Lancet 2011;377:1409-20. 